\title{
Preparation of Fly ash Based Adsorbents for Removal Active Red X-3B from Dying Wastewater
}

\author{
LI Jinping ${ }^{1, a^{*}}$, GAN Jinhua ${ }^{2, b^{*}}$, WU Liang ${ }^{1, \mathrm{c}}$ and YI Juan ${ }^{1, \mathrm{~d}}$ \\ ${ }^{1}$ School of Environmental Engineering, Wuhan Textile University, Wuhan, 430073, China \\ ${ }^{2}$ Yangtze River Fisheries Research Institute, Wuhan, 430050, China \\ asteven_ljp@sina.com, ${ }^{\mathrm{b}}$ rabbit_gjh@sina.com, ${ }^{\mathrm{c}} 1113884289 @$ qq.com, ${ }^{\mathrm{d}}$ yijuan@163.com
}

\begin{abstract}
Fly ash with a large number of active sites can occur with the adsorbent chemical and physical adsorption, and therefore have a strong adsorption capacity. The original fly ash and raw fly ash compared to the physical and chemical properties to a significant change. On the fly ash in industrial water treatment application were outlined. The purpose is to focus on the modification methods of fly ash and comparison of raw fly ash and fly ash in the effect of dyeing wastewater. Single factor test method; select the appropriate modifier to study the dosage, $\mathrm{pH}$, stirring time on the modification of adsorption properties of fly ash before and after. The results showed that the modified fly ash was better than the adsorption. Greatly improves on active red X-3B dye wastewater removal capacity, $\mathrm{pH}=5,6$, dosage is $5 \mathrm{~g} / \mathrm{L}$, the mixing time is $30 \mathrm{~min}$, COD removal rate reached $73.07 \%$. This modified material can be used as adsorbent for pre-treating dying wastewater.
\end{abstract}

Keywords: fly ash; activate and modify; X-3B dying wastewater; COD; color.

\section{Introduction}

Fly ash is a maximum number of solid waste materials. It will generate dust and pollute the atmosphere if placed in the open field without any disposal. If discharged into rivers and lakes, the rivers will be blockaded, the water bodies will be polluted and the aquatic organism will be poisoned. The toxic chemicals is still possible to infiltrate into the soil and enter the environmental system even if use landfill, eventually causing harm to the whole ecological environment and human health. Fly ash is a loose porous solid composite because of the large specific surface area, generally reach $2500 \sim 5000 \mathrm{~cm}^{2} / \mathrm{g}^{[1-2]}$. Therefore fly ash have a strong adsorption capacity because it have many active sites and can occur with the chemical adsorption and physical adsorption. There are certain flocculation and filtration $^{[3-5]}$.

Dyeing wastewater refers to the mixed wastewater ${ }^{[6]}$,which discharged from the

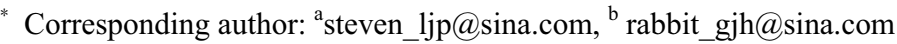


various processes in the dyeing process. The features of the dyeing wastewater is the complex components 、 high organic content、 deep color、 high demand of chemical(COD) relatively low demand of biochemical oxygen $\left(\mathrm{BOD}_{5}\right)$, poor biodegradability and large emission $^{[7-9]}$. According to 《Discharge standards of water pollutants for dyeing and finishing of textile industry $》$, in addition to the indicators of class III sewage changed little, the government raised the emission standards and other indicators of class I and class II effluent, including BOD、COD、color、suspended solids 、 ammonia 、 aniline、chlorine oxide and so on. But the quality of dyeing wastewater is COD: $800 \sim 2000 \mathrm{mg} / \mathrm{L}$, color: 200 to 800 times in average. Therefore the urgent problem of printing and dyeing industry is dyeing wastewater discharge .In this study, we study from specific Reactive Brilliant Red X-3B dying wastewater. We research on the resources and environmental properties of fly ash from the microscopic mechanism of morphology activity, etc. It provides a new way for the treatment and utilization of dyeing wastewater.

\section{Experimental Materials and Methods}

\subsection{Experimental materials and main instruments}

Fly ash used in this experiment is provided by a thermal power plant in Inner Mongolia. The processed is reactive brilliant red X-3B which belongs to the water-soluble dyes. The traits is maroon powder and the molecular weight is $614.49^{[10]}$. Experimental configured dyeing wastewater is $50 \mathrm{mg} / \mathrm{L}$ of reactive brilliant red X-3Bsimulated wastewater as a liquid and set aside.

The main instruments used in the tests are: spherical condenser, electric warming plate or electric furnace, buret, six joint blender, analytical balance, oven, spectrophotometer and other major equipment.

\subsection{Experimental methods}

The experiment studied the factors to the wastewater treatment, include the dosage $\mathrm{pH}$ and stirring time. In the first place, drying the fly ash material and then screened with a 200 mesh screen standby, Configuring 50mg / L of reactive brilliant red X-3B dye wastewater stand by. The method of modifying fly ash is that take six $200 \mathrm{~mL}$ beakers were compiled on the number; weigh $3 \mathrm{~g}$ raw fly ash by electronic scales and place them in six beakers; in six beakers were respectively added $24 \mathrm{~mL}$ concentration of $20 \%$ hydrochloric acid solution (the following are replaced with hydrochloric acid) $24 \mathrm{~mL}$ concentration of $20 \%$ sulfuric acid solution (the following are replaced with sulfuric acid)、 mixed with $16 \mathrm{~mL}$ of hydrochloric acid and $8 \mathrm{~mL}$ sulfuric acid , mixed with $12 \mathrm{~mL}$ of hydrochloric acid and $12 \mathrm{~mL}$ sulfuric acid mixed with $6 \mathrm{~mL}$ hydrochloric acid and $18 \mathrm{~mL}$ sulfuric acid 、 mixed with $4 \mathrm{~mL}$ hydrochloric acid and $20 \mathrm{~mL}$ sulfuric acid, stand $18 \mathrm{~h}$ after stir slightly; Dry the modified fly ash standby after filtrating. The best acid-modified type selection experiment is that take six $500 \mathrm{~mL}$ beaker, compiled on the number; the above modified six kinds of fly ash each placed $2 \mathrm{~g}$ into a beaker, add $200 \mathrm{~mL}$ dye wastewater; stirring $30 \mathrm{~min}$ and then standing $10 \mathrm{~min}$, filtering, measuring the absorbance.

\section{Results and Discussion}

\subsection{The selection of acid species}

Modifying the status quo ante of fly ash by different types and different proportions of 
hydrochloric acid and sulfuric acid, and then dispose the dyeing wastewater under the same conditions, the dosage of modified ash was $2.0 \mathrm{~g}$, the volume of wastewater was $200 \mathrm{ml}$, the time of stirring was $30 \mathrm{~min}$, and the value of $\mathrm{pH}$ was 3.5. The measured results are shown in Table 1. The microstructure of this fly ash before and after modified was shown in Fig.1.

\begin{tabular}{cccccccc} 
TABLE1 EFFECT & OF DIFFERENT & ACID MODIFY ON COLOR REMOVAL \\
\hline number & 1 & 2 & 3 & 4 & 5 & 6 \\
acid species & $\mathrm{HCl}$ & $\mathrm{H}_{2} \mathrm{SO}_{4}$ & & $\mathrm{~V}_{\mathrm{HCl}}:$ & $\mathrm{V}_{\mathrm{H} 2 \mathrm{SO} 4}$ & \\
\cline { 3 - 7 } & & & $2: 1$ & $1: 1$ & $1: 3$ & $1: 5$ \\
\hline absorbanceA & 0.308 & 0.773 & 0.799 & 0.789 & 0.770 & 0.819 \\
removal rate(\%) & 77.10 & 42.53 & 40.59 & 41.34 & 42.75 & 39.11 \\
\hline
\end{tabular}
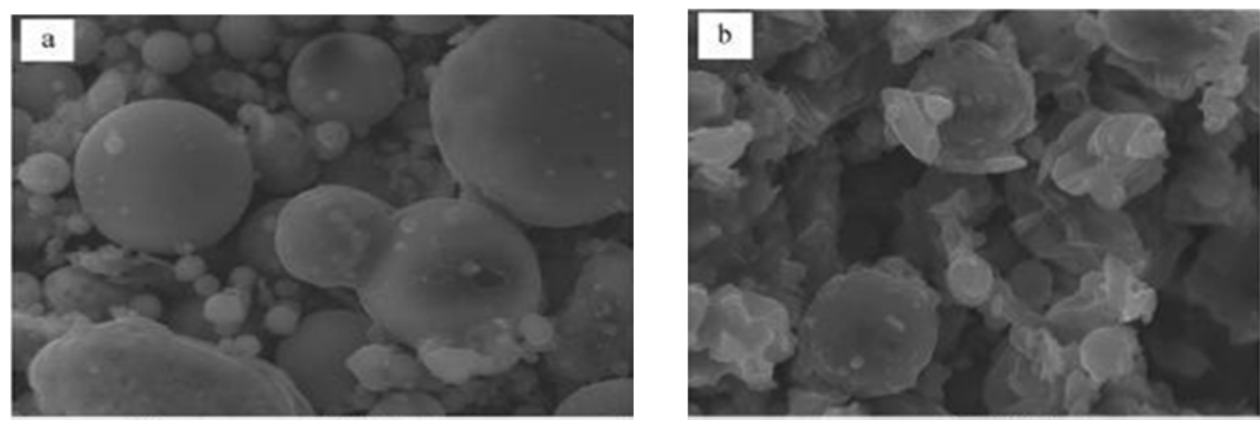

Fig.1 SEM of fly ash before and after modified (a:before modified, x500; b:after modified, x500)

As can be seen from Table 1, the treatment efficiency of the modified fly ash to dyeing wastewater was much higher than before the modification because the composition of fly ash containing $\mathrm{Al}_{2} \mathrm{O}_{3} 、 \mathrm{CaO} 、 \mathrm{Fe}_{2} \mathrm{O}_{3} 、 \mathrm{FeO}$ and other metal oxides. The results of acid leaching make these metal oxides react with acid and produce the absorbent and strong flocculate of inorganic salt, such as iron and aluminum sulfates, chlorides and other salts and so on. But different adsorbents have different adsorption decolonization on different dyeing wastewater. From the experimental results, fly ash modified with hydrochloric acid have better effect of removal to the reactive brilliant red X-3B dye wastewater than other acid modified, under the best conditions of other factors yet to determine, the removal has reached 77.10 percent. Therefore, use concentration of $20 \% \mathrm{HCl}$ to modify the fly ash in the following experiments.

\subsection{Ash dosage effect on the treatment effect}

Taking $200 \mathrm{~mL}$ reactive brilliant red X-3B wastewater and the concentration is $50 \mathrm{mg} / \mathrm{L}$. In this study, adding raw fly ash and modified fly ash to wastewater, the dosing rates were $2.5 \mathrm{~g} / \mathrm{L}, 5 \mathrm{~g} / \mathrm{L}, 7.5 \mathrm{~g} / \mathrm{L}, 10 \mathrm{~g} / \mathrm{L}, 12.5 \mathrm{~g} / \mathrm{L}$. Stirring for $30 \mathrm{~min}$ at $300 \mathrm{rad} / \mathrm{min}$ speed, filtering them after resting 10min, the measured results shown in Figure 1. From Fig.2, the adsorption rate of modified fly ash absorb the reactive brilliant red X-3B dye is rises with the dosage increase before the dosage is $1 \mathrm{~g}$.But the adsorption rate began to decline after the dosage of adsorbent more than $1 \mathrm{~g}$. This may be due to an excessive amount of fly ash such that the alkaline solution increases with the amount of fly ash added, the increase of $\mathrm{pH}$ influences the adsorption. The most appropriate dosage of hydrochloric acid modified fly ash is $2.5 \mathrm{~g} / \mathrm{L}$. It can be clearly seen from the graph that the adsorption properties of the fly ash greatly improve after modification. So the following experiments mainly 
implemented from the factors of modified fly ash.

\subsection{Effect of $\mathrm{pH}$ on modified fly ash to the reactive brilliant red $\mathrm{X}-3 \mathrm{~B}$ wastewater}

Fixing other conditions, the dosage of modified fly ash adopts the best dosage obtained in the above experiment, measuring the optimum $\mathrm{pH}$ by changing the $\mathrm{pH}$ of the solution. Taking $200 \mathrm{~mL}$ active red X-3B wastewater and the concentration is $50 \mathrm{mg} / \mathrm{L}$. The dosage of modified fly ash is $1 \mathrm{~g}$. Adjusting the $\mathrm{pH}$ of solution to 2 to $3 、 5$ to $6 、 7 、 8$ to $9 、 11$ to 12 respectively by adding $\mathrm{HCl}$ solution and $\mathrm{NaOH}$ solution. Stirring $30 \mathrm{~min}$ at $300 \mathrm{r} / \mathrm{min}$, then filtering after 10 min standing, the measured absorbance results are known in Fig.3. From Fig.3, the adsorption capacity increased with the value of $\mathrm{pH}$ rise when the $\mathrm{pH}$ is about 5.0 and the adsorption capacity decreased with the value of $\mathrm{pH}$ rise when the $\mathrm{pH}$ is greater than 5-6. This phenomenon is consistent with the previous results. Therefore, selecting the value of $\mathrm{pH} 5 \sim 6$ as the optimum $\mathrm{pH}$ in the following tests.

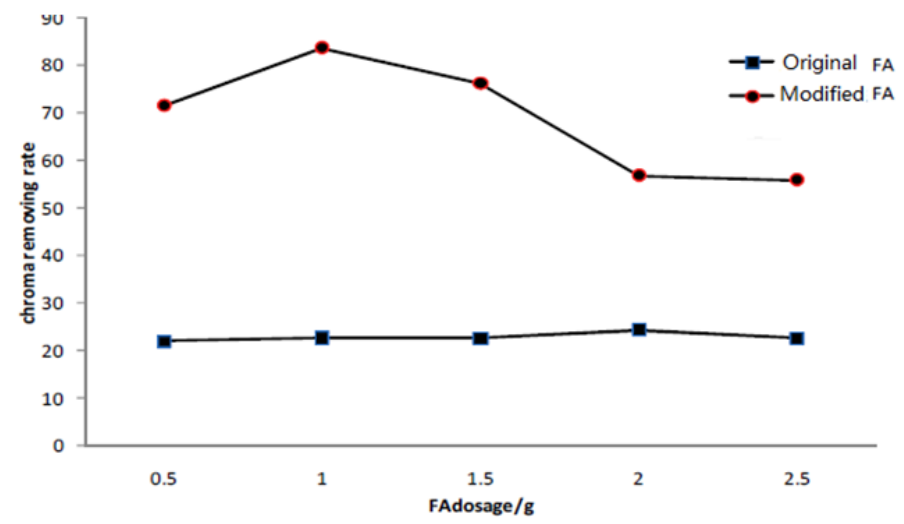

Fig.2 Effect of fly ash dosage on color removal

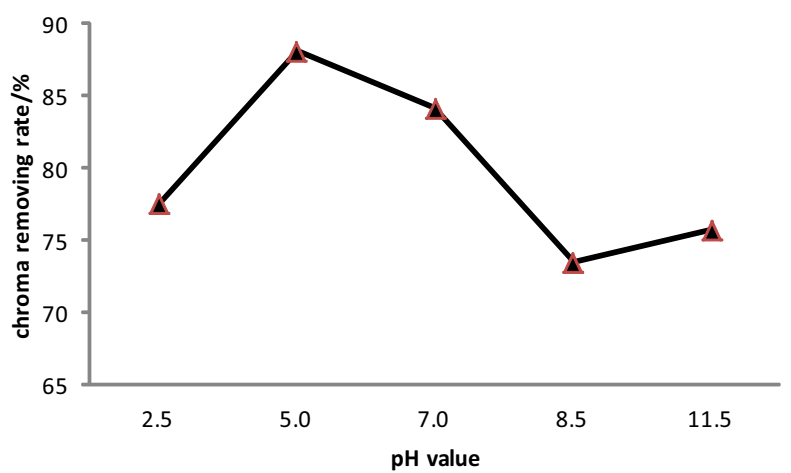

Fig.3 Effect of wastewater $\mathrm{pH}$ on color removal

\subsection{Effect of stirring time on the modified fly ash to the active red X-3B wastewater}

Fixing other conditions, the best dosage of fly ash was $1 \mathrm{~g}$ and the value of $\mathrm{pH}$ was 
adjusted to 5 to 6 .Messuring the effect of processing efficiency of fly ash by changing the mixing time. Taking $200 \mathrm{~mL}$ active red X-3B wastewater and the concentration is $50 \mathrm{mg} / \mathrm{L}$. The dosage of modified fly ash is $1 \mathrm{~g}$. Adjust the solution $\mathrm{pH}$ from 5 to 6 by adding $\mathrm{HCl}$.

Stirring them $10 \mathrm{~min} 、 15 \mathrm{~min} 、 30 \mathrm{~min} 、 45 \mathrm{~min} 、 60 \mathrm{~min}$ respectively at $300 \mathrm{r} / \mathrm{min}$ and standing $10 \mathrm{~min}$ before filtrating. The measured absorbance results are shown in Fig.4. As seen in Fig.4, removal is not high and there is an upward trend because fly ash has not reacted completely. The removal is reached the maximum at $30 \mathrm{~min}$ and the reaction is substantially complete. Stirring them continuously, leaving part of the unstable floc is broken and leaving the solution is cloudy because the time is too long. The removal rate decreased obviously ${ }^{[11-12]}$. The removal rate changed little because they were more stable after $45 \mathrm{~min}$. Thus, it can be seen that the optimum mixing time is preferably in $30 \mathrm{~min}$.

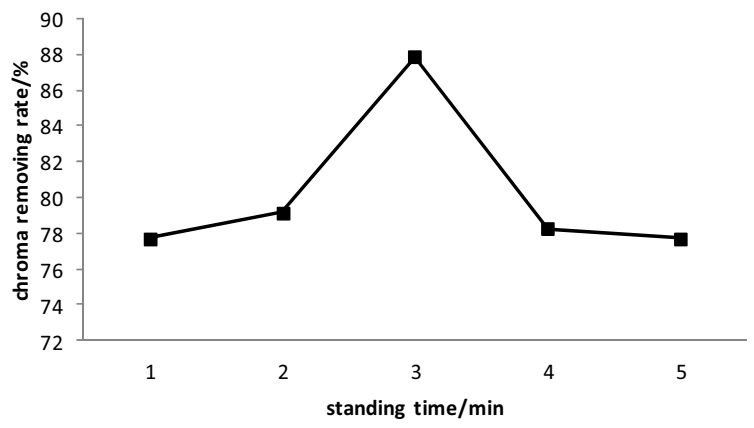

Fig.4 Effect of stirring time on color removal

\subsection{Effect of wastewater treatment under optimum conditions}

Using a single variable method in the previous experiments and eventually get a set of experiments that either the dosage or the $\mathrm{pH}$ or the mixing time were the best. Measuring this set of treated wastewater chromaticity、 $\mathrm{pH}$ and COD and the results are shown in Table 2. It's obviously that the modified fly ash has good effect on treating the active red $\mathrm{X}-3 \mathrm{~B}$ wastewater and the rate of removal can reach $87.88 \%$ under optimum conditions. It has significantly higher of removal than the unmodified and the better effect of treatment to dye wastewater in terms of color and the effluent COD. The keramchalite and the Purple aluminum vanadium iron generated by the acid-modified fly ash can release aluminum and iron ions in the role of the acid ${ }^{[13-14]}$. It can effectively reduce the potential of the particles suspended in the water and make the modified fly ash participate adsorption ${ }^{[15-16]}$. Therefore, the modified fly ash can not only effectively remove wastewater's chromaticity, but also reduce the wastewater's COD.

TABLE2 RESULTS OF WASTEWATER UNDER THE OPTIMAL CONDITIONS Parameter COD(mg/L) SS(mg/L) Chromaticity(times)

\begin{tabular}{lllc}
\hline Raw water & 250.8 & 90 & $2^{11}$ \\
Treating water & 30.4 & 30 & $2^{4}$ \\
Removal rate(\%) & 87.88 & 60 & 98.4 \\
\hline
\end{tabular}




\section{Conclusions}

The removal rate of raw fly ash handle the dyeing wastewater was $49.07 \%$, the removal rate of COD was $27.59 \%$, the color was 29 times and the $\mathrm{pH}$ was $3 \sim 4$. The best dosage of modified fly ash was $1 \mathrm{~g}$, the optimum $\mathrm{pH}$ was weak acid, $\mathrm{PH}$ was $5 \sim 6$ and the best mixing time was $30 \mathrm{~min}$.

The removal rate of COD could reach $87.88 \%$ when the modified fly ash handled with this active red X-3B wastewater under the modified adsorption conditions. The removal rate of SS reached 60 percent and the removal of color could up to $98.4 \%$. It could greatly improve the treatment effect of fly ash handle the wastewater after modification. The effect of modified fly ash handle the active red X-3B wastewater is obvious and the pollutant index was greatly reduced after handling. It provides convenient for subsequent processing and can greatly reduce the cost of processing.

\section{Acknowledgement}

This research was supported by a grant from National Natural Science Foundation of China(No.51208393), Hubei Department of Education Science Foundation (No.201304904), Natural Science Foundation of Hubei province(No.2014CFC1137) and the University Youth Grant(No.2012040). The authors would also like to thank the anonymous reviewers for their commenting of this paper.

\section{References}

1. Zhao Feng .Brief talk on the utilization of fly ash [J].Shanxi Architecture, 2010, 36(3):184-185.

2. Zheng Bin Guo, Liu Jun Tan, CuiJie Hu et al. Application of fly ash to waste water treatment in China[J].Water Resources Protection, 2007, 23(3):36-39.

3. V K Gupta, Imran Ali. Removal of lead and chromium from wastewater using baggasse fly ash-a sugar industry waste[J]. Journal of Colloid and Interface Science, 2004, 271(1):321-328.

4. Xiang HuiQiang, Mo ZanJiang. Application of fly ash in the treatment of printing and dyeing wastewater[J].Dyestuffs and Coloration

5. Zhu Hong Tao.Study on the adsorption of reactive brilliant blue modified fly ash[J].Techniques and equipment for environmental pollution control , 2005,6(3):53-56.

6. Y C Sharma, Uma, S N Singh et al. Fly ash for the removal of Mn(II)from aqueous solutions and wastewaters[J]. Chemical Engineering Journal, 2007, 13(2):319-323.

7. Yang ZiLi, Liu HongGuang, Gu Xi Hui. Modification of fly ash and its application to the treatment of oil-bearing wastewater[J].Industrial Water Treatment,2011,31(12):57-59.

8. Zhong Yu Feng, Xie Si Cai. An experimental study on treatment of phenol-containing 
wastewater with the modified fly ash[J].Journal Of Shanxi University Of Science And Technology ,2010,28(6):62-64.

9. Zhu Hong Tao. Study on the adsorption of reactive brilliant blue by modified fly ash $[\mathrm{J}]$.Techniques and equipment for environmental pollution control , 2005,6(3):53-55.

10. Chen Wan Mei,LiBaoXia,Chen Yi Bin.Removing ammonia-nitrogen from waste water by modified fly ash[J].Journal of Fuzhou University (Natural Science Edition), 2012, 40(1):138-142.

11. Zhang Xin,Wang Xin Dong.A study on removal of phosphorus from waste water by modified fly ash[J].Shandon Chemical Industry, 2006 (35): 7-10.

12. ReyadShawabkeh, Adnan AI-Harahsheh, Malik Hami et a1. Conversion of oil shale ash into zeolite for cadmium and lead removal from wastewater[J]. Fuel, 2004, (83):981-985.

13. Vimal Chandra Srevastava, Indra Den Mail,Indra Mani Mishra . Adsorption thermodynamics and isosteric heat of adsorption of xic metal ions onto bagasse fly ash(BFA)and rice busk ash(RHA) $[\mathrm{J}]$. Chemical Engineering Journal, 2007, 13(2):267-278.

14. Vinod $\mathrm{K}$ Gupta, C KJain, Imran Ali et al. Removal of cadmium and nickel from wastewater using bagasse fly ash-a sugar industry waste[J]. Water Research, 2003, (37):4038-4044.

15. Y C Sharma, Uma, S N Singh et al. Fly ash for the removal of Mn(II)from aqueous solutions and wastewaters[J]. Chemical Engineering Journal, 2007, 13(2):319-323.

16. Serpil Cetin, Erol Pehlivan. The use of fly ash as a low cost, environmentally friendly alternative to activated carbon for the removal of heavy metals from aqueous solutions[J]. Colloids and Surface A: Physicochemical Engineering Aspects, 2007, 29(8):83-87. 